\title{
European space panel picks new priorities
}

\section{Alison Abbott, Munich}

The European Space Agency (ESA) is being asked to approve a package of missions that includes a major project to Mercury and a significant part in the NASA-led Next Generation Space Telescope (NGST). The move is intended to meet the needs of space scientists across a range of disciplines.

Both projects received the backing of ESA's Space Science Advisory Committee (SSAC) last week, and are scheduled for launch in about 2009. The panel also approved a solar mission, the Solar Orbiter, and an astrometry mission, GAIA, both scheduled for launch around 2012.

If approved - as is widely expected the mission to Mercury will be ESA's fifth major 'cornerstone' mission, with a budget of around 600 million euros (\$514 million). It is known as Bepi Colombo, after the Italian space pioneer Giuseppe Colombo who in the 1960s worked out how to use the gravity fields of planets to 'slingshot' a spacecraft towards its destination, a technique used on NASA missions to Mercury in the 1970 s.

Bepi Colombo will use a new solarelectric propulsion system. It will have a lander to investigate Mercury's surface and remote-sensing instruments to study the planet's surface and magnetosphere.

ESA will contribute around 150 million euros to the NGST - about $15 \%$ of its estimated total cost. This is comparable to ESA's involvement in the Hubble Space Telescope.

Bernard Seery, NGST's project manager at the the Goddard Space Flight Centre near Washington DC, says he is delighted but not surprised by the recommendation. "ESA and NASA have been working together on the development of the NGST concept since its inception," he says.

The Canadian Space Agency will take a 5\% stake in the NGST, and some European countries may increase their participation. Italy has offered to add a further ten million euros, to be handled by ESA, and the United Kingdom is believed to be negotiating a bilateral agreement with NASA.

As with Hubble, ESA will contribute to the spacecraft as well as its instruments. It is slated to provide the NGST's near-infrared multi-object spectrometer, an innovative apparatus that will allow about 100 celestial objects to be observed at once.

In juggling the interests of researchers working on the Solar System, astronomy and fundamental physics, the SSAC decided to recommend that GAIA - another cornerstone mission - be launched unusually soon after Bepi Colombo.

ESA's earlier astrometry mission, Hipparcos, completed its data collection in 1997, and ESA is keen to ensure that the groups analysing these data do not disperse before

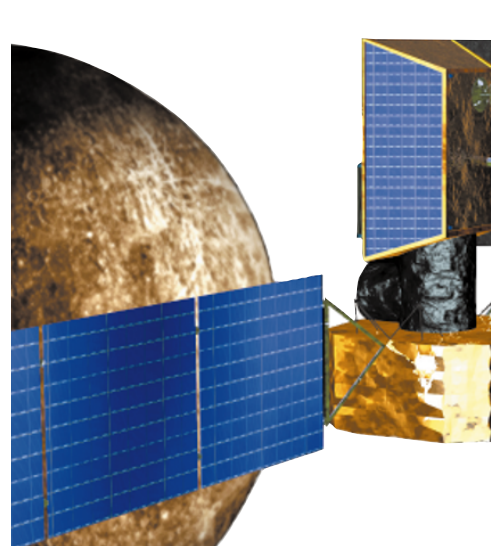

GAIA is developed. "A delay in its development would be a risk for the continuity of these groups," says Jordi Torra, an astronomer at the University of Barcelona.

The SSAC recommended the Solar Orbiter as its third 'flexible' mission, rather than a Mars mission as some had predicted. This was partly out of concern that taking on Bepi Colombo on top of a number of other large missions — including Mars Express and the cornerstone mission to comet Rosetta, both due for launch in 2003 - might overstretch Europe's planetary scientists.

Also, the joint NASA/ESA mission to Sat- urn, Cassini-Huygens, launched in 1997, will reach its destination in 2004. "Research groups must be available to take on these projects," says Giovanni Bignami, science director of the Italian Space Agency. "There is some concern that in planetary sciences they are getting saturated."

The SSAC also recommended that ESA uses a future 'flexible' mission to participate in another planned NASA-led project to detect gravity waves. ESA's Space Policy Committee will decide formally on the new missions next month.

Additional reporting by Xavier Bosch, Barcelona.

\section{NASA reaches out to universities}

\section{William Triplett, Washington}

The US space agency NASA is trying to bring more university researchers - with fresh ideas - into its fold. But although they welcome the initiative, many researchers are waiting to see how much money NASA will put where its mouth is.

In recent years, budget cuts have forced NASA to reduce its research spending. As a result, universities have felt neglected, and have criticized the agency for becoming too inward-looking. The new effort, dubbed the 'University Initiative', is intended to change that, says Randall Correll, a NASA spokesman.

Spence Armstrong, a US Air Force veteran who has been with NASA since 1991 - most recently as head of the agency's aeronautics and space transportation section - will oversee the initiative. In February he was appointed senior adviser to NASA administrator Dan Goldin.

The scheme will be launched next month, when NASA will hold the first of several planned 'cyber-conferences' in Washington. The conference, to be broadcast live over a NASA cable television channel as well as the Internet, is intended to develop ideas for collaboration in four areas: space flight, space science, Earth science and aerospace technology.

During the conference, Armstrong and Goldin will invite proposals from university researchers. Although they must ultimately benefit NASA, proposals will not have to be strictly space-related.

"If you look at recent NASA activities, some of the technologies we're starting to invest in, such as biologically inspired engineering, these types of things show that we're expanding," says Correll. "Things have become much more complicated than just building a rocket ship and going into space."

For example, says Correll, a robotic mission to Mars to search for signs of life might make use of studies of life on Earth. “Once you've studied what life is like here, you might change your type of sensor sweeps that you put on your spacecraft."

But despite a 7\% increase in NASA's budget, Armstrong acknowledges that the agency will need even more money in the next budget to underwrite the initiative. $\mathrm{He}$ will not name a figure, but he has told his 


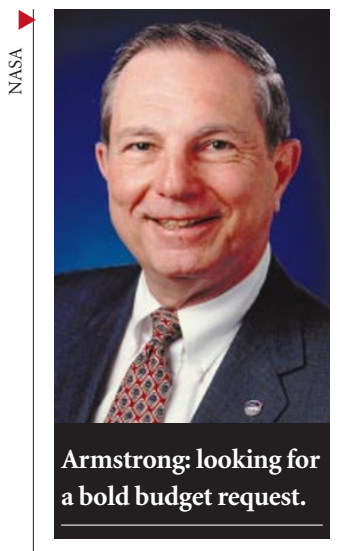

budget designers to be "reasonably bold" in their request.

Another variable is the US presidential election in November. President Bill Clinton's administration will prepare the next federal budget before then, but Congress will not take it up until after the new administration proposes any adjustments.

But some observers are optimistic. "Armstrong has already come to us and asked our membership for ideas and advice," says Jacques L'Heureux, director of University Relations for Space Sciences at the Universities Space Research Association. "He seems very serious."

University researchers have been "very receptive", says Correll. But, he adds, "the biggest fear, as you might expect, is that when the government says 'we're here to help', the feeling is that talk is easy". thttp://www.hq.nasa.gov/office/codea/codeac/ www/news.html

\section{Germline gene therapy needs tight control, says US panel}

Paul Smaglik, Washington

Tight regulation and oversight will be needed of efforts to make genetic modifications to human cells that can be passed on to offspring, a panel set up by the American Association for the Advancement of Sciences said this week.

Proponents of germline gene therapy have previously asked that it should not be regulated more heavily than other kinds of experimental medicine (see Nature 392,317; 1998). Such a move, they argue, could slow efforts to develop germline gene therapy, which aims to combat genetic diseases by targeting cells in a prospective parents' testes or ovaries, or by conducting gene therapy on an embryo.

But the recommendation of the AAAS panel reflects its conclusion that, for all its promises, germline therapy remains problematic because unintended genetic changes could be passed to a new child along with intended benefits.

"There would need to be compelling scientific evidence to prove that these procedures are safe and effective," says Mark
Frankel, the report's co-author and director of the AAAS Scientific Freedom, Responsibility and Law programme. Such evidence has not yet materialized.

Rather than pursuing germline therapy, the AAAS report urges scientists to focus on making changes in cells that will not be passed to the next generation. It also encourages more research into methods to correct genetic 'misspellings'.

Without first improving either of those two approaches, germline gene therapy can be neither safe nor effective, Audrey Chapman, director of an AAAS program on biomedical ethics and a co-author of the report, said at a press conference on Monday.

Robert Cook-Deegan, a Georgetown University bioethicist, called for a new body to be set up to monitor germ line gene therapy experiments in animals, perhaps modelled on the National Institute of Health's Recombinant DNA Advisory Committee (RAC). It would eventually decide whether human clinical trials should go forward.

| http://www.aaas.org/spp/dspp/sfrl/germline/main.htm

\section{Case of the stolen Enigma machine takes cryptic turn}

Natasha Loder, London

It is a riddle wrapped in a mystery inside an Enigma. Who stole a rare version of the machine that the Germans used to encrypt military secrets during the Second World War? And does an anonymous note contain a coded clue to the thief's identity?

The 'Enigma machine' was stolen in April from Bletchley Park Museum in Buckinghamshire. During the war, Bletchley Park was home to a team of mathematicians and cryptographers who worked on cracking coded German military communications.

In the past weeks the museum has received two strangely worded, anonymous letters offering to return the machine for a five-figure sum. The first starts: "I have been asked by the current owner the above Enigma machine, who purchased it in good faith (in good faith being the operative words) to say and tell you now today, the unwitting person have no desire of depraving [sic] your august self or any one the pleasure to see it again." It was sent from the Midlands of England, and appears to have been written on a typewriter dating from the Second World War.

The museum's chief executive, Christine Large, says the episode has "an element of mystique which is completely in keeping

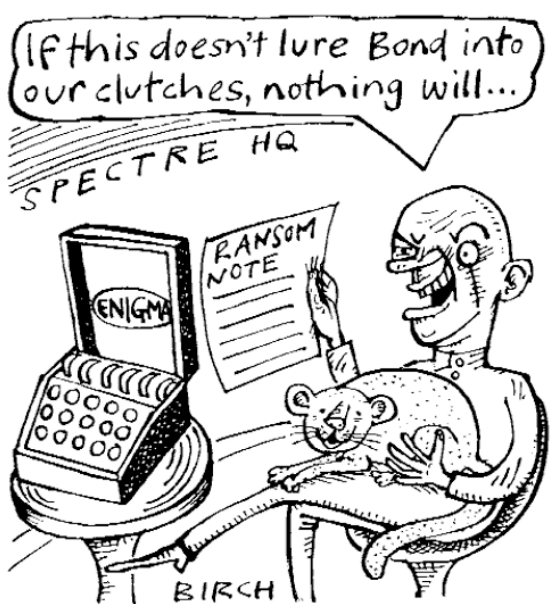

with the history of the park. It is an unusual letter but seems genuine. It doesn't surprise me that the author is a middleman. We really want to assure them that our priority remains getting [the machine] back in good condition."

The museum is now waiting for the next contact. "We have made it very clear that, assuming there is no criminality involved, that police will not prosecute," says Large. The machine was on long-term loan from the Government Communications Head- quarters in Cheltenham, which acquired it after the war.

There are several hundred Enigma machines on the market. But the stolen one, which carries the serial code G 312, is a very rare four-rotor machine used by the Abwehr German military intelligence. The only other known example is owned by the US National Security Agency.

Bletchley Park became the home to the UK Government Code and Cypher School in 1939; the teams that worked to crack the Enigma machines were housed in wooden huts. The Germans updated the machines over the years, but a series of breakthroughs by cryptographers meant that German messages could be decoded for much of the war.

The Buckinghamshire police say the letters are their best lead so far. The first letter ends in a word - which is not being released by police - that some have suggested may be in code. But Large says that the word is recognizable, although not English. The machine featured in an Interpol 'wanted' poster in June, but the police say they have no evidence that it has left the country.

http://www.bletchleypark.org.uk

http://www.interpol.int/public/workofart/ data/1003/1003713.asp

NATURE $\mid$ VOL 407 21 SEPTEMBER 2000 |www.nature.com 